\title{
La búsqueda de China de recursos naturales en América Latina
}

\author{
Felipe Freitas da Rocha y Ricardo Bielschowsky ${ }^{1}$
}

\section{Resumen}

Este artículo describe y analiza la búsqueda de China de recursos naturales en América Latina, en particular petróleo, hierro, cobre y soja, que representan más del $70 \%$ de las importaciones del país desde la región, una búsqueda motivada por el crecimiento acelerado y la escasez relativa de recursos naturales en China y su planificación a largo plazo que atribuye a la región el papel de importante proveedora. En el caso del petróleo, el acceso tiene lugar principalmente mediante financiamientos con contrapartidas de petróleo e inversiones directas, mientras que en el del hierro y el cobre se obtiene mediante inversiones directas e importaciones. La manera elegida por China para garantizar la seguridad en el abastecimiento parece ser el control físico del recurso. En el caso de la soja, el camino elegido ha sido la importación cada vez más intermediada por empresas mercantiles presentes en la región y recientemente adquiridas por China.

\section{Palabras clave}

China, importaciones, recursos naturales, petróleo, mineral de hierro, mineral de cobre, soya, relaciones económicas, desarrollo económico, dependencia económica, América Latina

\section{Clasificación JEL}

$$
\text { O13, Q17, Q37 }
$$

\section{Autores}

Felipe Freitas da Rocha es Doctorando del Programa de Posgrado en Economía del Instituto de Economía de la Universidad Federal de Río de Janeiro (UFRJ), Brasil. Correo electrónico: felipefreitasdarocha@hotmail.com.

Ricardo Bielschowsky es Profesor Asociado del Instituto de Economía de la Universidad Federal de Río de Janeiro, Brasil. Correo electrónico: ricardo.bielschowsky@gmail.com.

\footnotetext{
1 Este artículo es una síntesis de la tesis de maestría defendida por Rocha (2016) y orientada por Bielschowsky.
} 


\section{Introducción}

China está construyendo cadenas mundiales de suministro de bienes primarios. Para ello, busca comercializar con el mayor número posible de países productores y, valiéndose de sus más de 3,5 billones de dólares en reservas, incentiva a sus empresas de recursos naturales a invertir en el exterior y conduce a sus bancos públicos a realizar préstamos con contrapartidas en petróleo y gas alrededor del mundo.

La región latinoamericana desempeña un importante papel en la estrategia de China de acceso a recursos naturales a escala mundial. Entre 2000 y 2015, el valor de las importaciones de China con origen en América Latina pasó de 5.000 millones a 103.000 millones de dólares.

En este artículo se describe la intensa búsqueda de recursos naturales que China ha realizado recientemente en América Latina. Se examinan, en particular, las diferentes estrategias de China en los casos del petróleo, el mineral de hierro, el mineral de cobre y el cobre refinado y la soja y sus derivados, que en 2015 representaron aproximadamente el 70\% de las importaciones de China desde América Latina.

El artículo se divide en cuatro partes, además de esta introducción y la conclusión. En la segunda sección se contextualiza el objeto del trabajo en términos teóricos y empíricos. En la tercera se examina el acceso chino al petróleo latinoamericano y se argumenta que, por consideraciones de racionalidad económica, las empresas petroleras de China venden gran parte del petróleo latinoamericano bajo su control a los Estados Unidos y a su propia región y adquieren el combustible de mercados más próximos a China, por sus características más compatibles con su capacidad de refinación. En la cuarta sección se describe el acceso chino a los minerales metálicos latinoamericanos, haciendo hincapié en el comercio y la inversión extranjera directa. El análisis se concentra en el cobre (mineral y cobre refinado) y el mineral de hierro. En la quinta sección se muestra el acceso chino a la soja latinoamericana y se analiza la manera en que la estrategia de China de inversión en empresas mercantiles evita la incertidumbre jurídica de la compra de tierras en América Latina. El trabajo se concluye con algunas consideraciones sobre la forma en que América Latina acoge la búsqueda de China de recursos naturales, considerada poco adecuada para el desarrollo latinoamericano?2.

\section{Consideraciones teóricas y empíricas}

\section{La búsqueda de China de recursos naturales y el enfoque centro-periferia}

Si bien este artículo es esencialmente empírico, el interés en el tema se relaciona con el enfoque centro-periferia de la Comisión Económica para América Latina y el Caribe (CEPAL) y el abordaje "histórico-estructural" que caracteriza a la institución. El estudio fue motivado por la percepción de que la actual inserción de China en América Latina refleja una nueva tendencia histórica que afecta las estructuras productivas de la región, fortaleciendo el modelo exportador basado en bienes primarios y, en particular, por la percepción de que esa inserción se relaciona con un nuevo tipo de relaciones entre el centro y la periferia, al cual la región parece estar cada vez más subordinada, que incluye a China como nuevo "eslabón" de la dependencia de las economías

\footnotetext{
2 Cabe señalar que en el artículo no se abordan las inversiones de China en infraestructura de acceso a recursos naturales por tratarse de una modalidad aún embrionaria (aunque señalada en forma recurrente por la prensa, como en el caso de un posible canal interoceánico en Nicaragua y de una eventual ferrovía para conectar el Brasil con el litoral del Perú).
} 
centrales. Al analizar el acelerado movimiento reciente de los intereses chinos en la región, se busca contribuir al conocimiento del proceso de reconfiguración de las relaciones centro-periferia en curso en América Latina.

Como es sabido, el enfoque centro-periferia data de los orígenes de la CEPAL ${ }^{3}$. Comenzó en los años inaugurales del organismo, de la mano de Prebisch (Prebisch, 1949; CEPAL, 1951), y se basó en el examen de los efectos de la evolución de las economías centrales en los países de la región y el descubrimiento de una tendencia desfavorable a largo plazo, en función del lento progreso técnico y el deterioro de los términos de intercambio.

Se argumentó que, de no haber una industrialización bien conducida - considerada necesaria pero problemática, debido a la escasa diversidad productiva, la heterogeneidad estructural y la institucionalidad poco adecuada a la inversión productiva y al progreso técnico (Rodríguez, 1981 y 2006; Bielschowsky, 1998 y 2009) - la inserción internacional de la región estaba destinada a aumentar la distancia con respecto a los niveles de ingreso y riqueza de los países del centro. Con la teorización sobre la "dependencia", en los años sesenta y setenta, se incorporó en el enfoque la visión de que el proceso de industrialización en curso en América Latina dependía tecnológica y financieramente del centro 4 .

En la "década perdida" de 1980, debido a la deuda con los bancos que paralizó a la región y de una primera percepción de la "financierización" (CEPAL, 1985) y la pasividad ante la revolución tecnológica en curso, el enfoque centro-periferia permaneció subyacente a la tradición de la economía política sobre la realidad regional - aunque la frecuencia de uso de los conceptos "centro-periferia" y "dependencia" pueda haber disminuido en esos años de declive de la teoría del desarrollo. En la década de 1990, la clara percepción de comportamiento "periférico" se reforzaría por la idea de subordinación a la financierización y a la volatilidad de capitales, generadoras de gran inestabilidad macroeconómica en América Latina (CEPAL, 1995), y a las condiciones desfavorables de inserción internacional latinoamericana en la globalización productiva (Di Filippo, 1998).

A partir del inicio de la década de 2000, la actuación de China en la región -ya en su admitida calidad de nuevo actor del centro - constituye el nuevo elemento que ha de entenderse en detalle, en el marco de la concepción centro-periferia, y merece por esa razón una atención empírica especial. El presente estudio contribuye a esa tarea.

Cabe observar que, además de ser relativamente escasos, los trabajos sobre la búsqueda de recursos naturales en América Latina realizados hasta ahora no se han concentrado en la teorización convencional sobre la internacionalización de las empresas multinacionales. Hay tres razones que explican la orientación de esos trabajos y también la que se sigue en este artículo.

En primer lugar, y como se muestra en este trabajo, la inversión extranjera directa (IED) convencional, además de relativamente escasa en varios sectores de recursos naturales en América Latina (como metales y alimentos), constituye solo una de las modalidades de acceso de China a dichos recursos.

En segundo lugar, la IED de China ya existente en la región se concentra casi totalmente en el acceso a recursos naturales, de manera que la teorización convencional sobre el tema tiene una capacidad explicativa limitada. Por ejemplo, de poco vale en ese caso la importante teorización de Dunning (1988) sobre la búsqueda de mercado interno, mano de obra barata y activos tecnológicos.

\footnotetext{
3 Véase una buena reseña del enfoque centro-periferia en Love (2007).

4 Expresada tanto en las versiones no marxistas, como por ejemplo la de Sunkel (1970), como en las marxistas, como la de Dos Santos (1970).
} 
En tercer lugar, y aún más relevante, el comportamiento de las empresas multinacionales de China, y en especial las del sector de recursos naturales, está esencialmente dictado por los intereses de planificación del Gobierno chino, centralizado y encabezado por el Partido Comunista, que dicta la orientación general sobre las relaciones del país con América Latina, en el entendido de que la región es una importante fuente de recursos naturales en el mundo.

La literatura sobre la estrategia de China de búsqueda de recursos naturales muestra que el interés del Gobierno de China se relaciona de manera central con los objetivos de seguridad nacional y autonomía para crecer a largo plazo (Corrêa, 2015; Jian, 2011; Peine, 2013; Sharma, 2014). Esos objetivos están probablemente seguidos por otros tres, a saber: reducir los precios de los productos básicos que necesitan, encontrar alternativas para la aplicación de las reservas externas de China (excesivamente aplicadas en títulos del tesoro estadounidense) y disminuir la presión sobre la apreciación del tipo de cambio. Así, es razonable suponer que las empresas multinacionales de China que actúan en el ramo de los recursos naturales, cuyos principales puestos de mando se cubren según indicaciones del Comité Central del Partido Comunista de China, sean estimuladas a buscar inversiones, en el mundo en general y en América Latina en particular, en calidad de prestadores de servicios estratégicos al Gobierno chino. Aunque eso no signifique que dejen de tener objetivos de rentabilidad, la conducta de esas empresas en su internacionalización en América Latina corresponde a un campo de investigación todavía por explorar y a una labor analítica todavía por realizar.

En el presente artículo se definen, en forma introductoria, algunos patrones de inserción de China en América Latina, que se diferencian según los sectores y transmiten una sensación de adaptación pragmática de China a los contextos de competencia de cada sector. Sin embargo, no se busca iniciar en este estudio una tipología según los comportamientos específicos de las empresas en cada sector. Es probable que en futuros trabajos se combine el principio de que las empresas de China están influenciadas por el Estado en sus decisiones de inversión en América Latina con la interpretación teórica convencional sobre el comportamiento de las empresas transnacionales.

A diferencia de la teorización sobre las multinacionales, el aporte empírico de este artículo tiene mayores vínculos con la línea investigativa sobre la "maldición de los recursos naturales". Como es sabido, el trabajo de Sachs y Warner (1995) renovó un antiguo debate sobre si los recursos naturales serían una bendición o una maldición. Los autores presentaron evidencia empírica y verificaron la existencia de una relación negativa entre, por una parte, los recursos naturales y su predominio en el modelo de exportación y, por otra, el crecimiento económico. Existen diversas explicaciones para ello, que van desde la teoría de la enfermedad holandesa y la teoría del crecimiento por exportación de bienes primarios (staple theory) a teorías institucionalistas que argumentan que la abundancia de recursos naturales está relacionada con barreras a la democracia, la captura del Estado, la corrupción y el estallido de guerras civiles ${ }^{5}$.

Como es obvio, si se aplica al caso de la búsqueda de China de recursos naturales en América Latina, la hipótesis natural de la maldición de los recursos naturales sería que, al intensificar las actividades exportadoras basadas en bienes primarios, el efecto chino en el desarrollo latinoamericano tiende a ser poco favorable. En ese sentido, no sería distinta de las conclusiones basadas en la teorización de Prebisch, a fines de la década de 1940 y en la década de 1950, sobre las relaciones centro-periferia, no por casualidad considerada una de las teorías precursoras de la hipótesis de la maldición de los recursos naturales. Entre los problemas de la especialización exportadora basada en bienes primarios, en la teorización cepalina, se destaca el argumento de su escasa capacidad innovadora y de encadenamientos productivos que tienden a "escapar" al exterior, mediante importaciones, frenando el crecimiento. No menos relevantes son los argumentos de que

\footnotetext{
5 Véase, por ejemplo, Maciel (2015), que hace una extensa reseña de la literatura sobre la maldición de los recursos naturales y sus distintos enfoques.
} 
esa especialización sujeta a las economías al deterioro de los términos de intercambio y tiende a exponerlas a una elasticidad-ingreso de la demanda de las importaciones mayor que la elasticidadingreso de la demanda mundial de sus exportaciones, generando desequilibrios en la balanza de pagos y, en consecuencia, frenando el crecimiento y el desarrollo.

En los últimos años, la CEPAL ha contribuido con un enfoque que presenta cierta proximidad con el de la maldición de los recursos naturales, por medio de trabajos en la línea de la "gobernanza de los recursos naturales" (CEPAL, 2014, Bárcena y Prado, 2016; Altomonte y Sánchez, 2016). Si bien en el estudio aquí presentado no se evalúan los efectos de las inversiones en recursos naturales en el desarrollo, en las consideraciones finales del artículo se presentan argumentos en sintonía con esa línea argumentativa.

\section{La importancia de los recursos naturales latinoamericanos para China}

China, país continental de 9,5 millones de kilómetros cuadrados, posee grandes recursos fósiles (carbón, petróleo, gas natural), el mayor potencial hidroeléctrico del mundo, una significativa extensión de tierras agrícolas y considerables reservas metálicas. No obstante, examinado a la luz del tamaño de su población y de su economía, el cuadro dista mucho de ser de abundancia. Por ejemplo, aunque concentra el 19\% de la población y genera el 16,5\% del producto interno bruto (PIB) mundial, China tiene, respectivamente, el $13 \%$, el $8,5 \%$, el $4 \%$, el $2 \%$ y el $2 \%$ de las reservas de carbón, mineral de hierro, mineral de cobre, petróleo y gas natural del mundo, además del 10\% de las tierras agrícolas y el $6,5 \%$ del agua dulce.

La escasez relativa se reveló en toda su intensidad con el acelerado crecimiento. En los últimos 35 años, el PIB chino creció a una tasa media del 10\% al año y transformó a China en la segunda mayor economía del planeta, volviendo su producción y consumo cada vez más dependientes de la importación de productos primarios.

Además de la escasez relativa, la producción de materias primas en China presenta diversos problemas específicos, que dificultan aún más un aumento significativo de la oferta interna de recursos naturales: principales campos petrolíferos maduros y producción en declive (EIA, 2015); alto costo de producción de mineral de hierro y bauxita (Carvalho y otros, 2014; Yu, 2011); baja relación entre reservas y producción de diversos minerales, como cobre (17 años), manganeso (15 años), plomo (7 años) y cinc (8 años), entre otros. Con respecto a la soja, la política de seguridad alimentaria volvió la producción de cereales más atractiva que el cultivo de la oleaginosa (Gale, Hansen y Jewison, 2015; Wong y Huang, 2012; Sharma, 2014).

En 1996, el país asiático se convirtió en importador neto de petróleo y soja y, en 2007 y 2009 , respectivamente, de gas natural y carbón. Las importaciones netas de petróleo aumentaron de 1,2 millones de barriles diarios en 2000 a 6,7 millones en 2015; las de mineral de hierro crecieron de 44 millones de toneladas finas en 2000 a cerca de 580 millones en 2015; las de cobre se incrementaron de 1,1 millones de toneladas finas en 2000 a 7,2 millones en 2015; y las de soja, que eran de 10 millones de toneladas en 2000, llegaron a más de 82 millones en 2015 . El grado de dependencia de las importaciones de recursos naturales en China, medido como proporción entre importaciones netas y consumo, ya alcanza el $60 \%$ en el caso de los principales productos básicos, como el petróleo, el cobre y el mineral de hierro, mientras que en el de la soja asciende al 85\% (véase el gráfico 1).

\footnotetext{
6 En este estudio el cobre incluye tanto concentrados de este metal como cobre refinado.
} 
Gráfico 1

China: grado de dependencia de las importaciones de materias primas seleccionadas, 1992-2014

(En porcentajes)

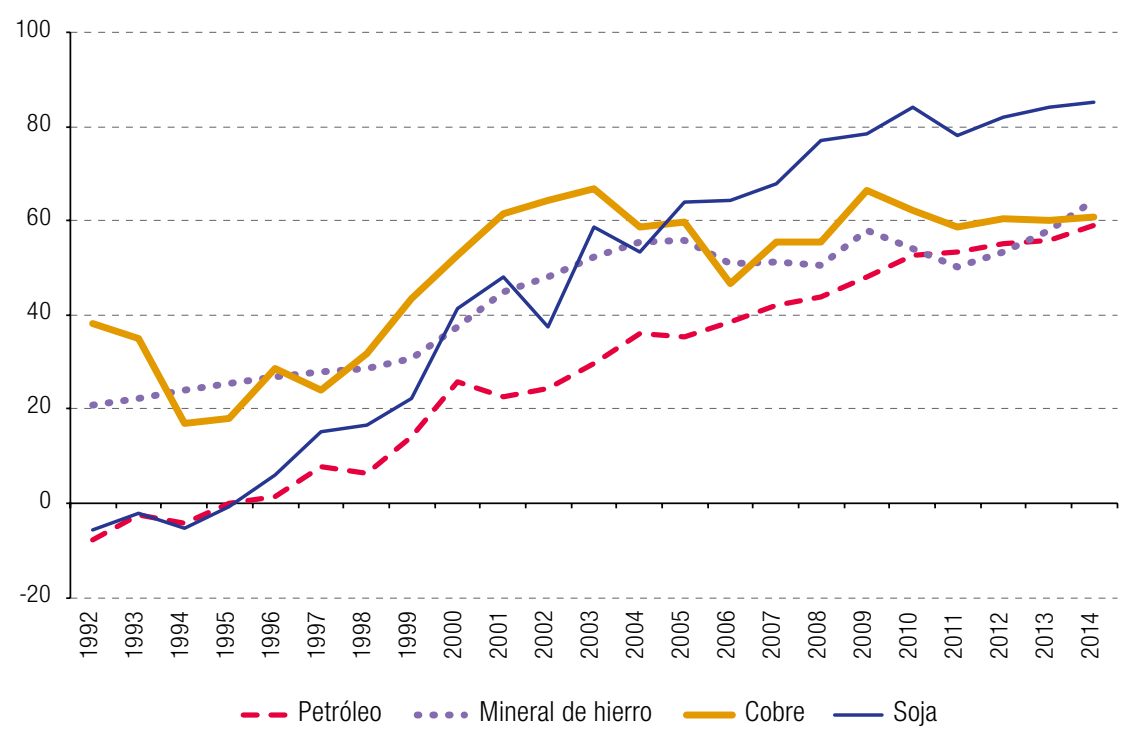

Fuente: Elaboración propia, sobre la base de F. F. Rocha, "Acesso chinês a recursos naturais na América Latina", Río de Janeiro, Instituto de Economía, Universidad Federal de Río de Janeiro (UFRJ), 2016.

Como señala Medeiros (2011), debido a la combinación del proceso de urbanización con el de industrialización pesada, el patrón de acumulación chino se vuelve intensivo en el uso de recursos naturales. A propósito, cabe señalar que, incluso con el cambio previsto hacia un mayor enfoque en el consumo interno como fuente de crecimiento, las proyecciones indican una elevada necesidad de importación de productos básicos basados en recursos naturales a mediano y largo plazo (Rocha, 2016).

Las modalidades de China de acceso a los recursos naturales se diferencian según los sectores. El sector petrolero absorbe la mayor parte de los financiamientos chinos a la actividad productiva en América Latina, por medio de préstamos con contrapartidas en petróleo (Gallagher, Irwin y Koleski, 2013). El petróleo, el cobre y el hierro reciben la mayor parte de la IED de China en América Latina, realizada por empresas públicas (Chen y Pérez-Ludeña, 2014). En el caso de la soja, en razón de dificultades legales para la compra de tierra, la estrategia fue adquirir dos empresas mercantiles internacionales ya presentes en la región y buscar transformarlas en una gran operadora en América Latina, en competencia con las cuatro principales empresas comercializadoras de materias primas, Archer Daniels Midland (ADM), Bunge, Cargill y Louis Dreyfus, conocidas colectivamente como las ABCD.

La relación es profundamente desigual: desde la perspectiva de China, América Latina es sobre todo una región proveedora de materias primas y, como se argumenta en la conclusión, los Gobiernos y agentes económicos de América Latina tratan la demanda de China simplemente de acuerdo con oportunidades típicas de mercado y no como un elemento de desarrollo sostenible a largo plazo ${ }^{7}$.

\footnotetext{
7 Esto no significa que China no realice inversiones en la industria de transformación y en servicios en América Latina, sino solamente que esos sectores no se consideran prioritarios y las inversiones en ellos todavía son embrionarias en la región.
} 


\section{El acceso chino al petróleo latinoamericano}

Entre 2000 y 2015, el consumo chino de petróleo se duplicó con creces, al pasar de 4,7 millones a 10,8 millones de barriles diarios. Este rápido crecimiento ha sido impulsado, principalmente, por el intenso aumento del consumo de gasolina y diésel en el sector de transporte, a raíz del aumento de la flota de vehículos (Rosen y Houser, 2007; AIE, 2012). Si bien la industria también es un importante consumidor, su participación en la demanda ha disminuido, al pasar del 50\% en 2000 al 35\% en 2013.

Según la Agencia Internacional de la Energía (AIE), la demanda de China de petróleo registrará un incremento de casi 5 millones de barriles diarios entre 2014 y 2040, en el marco de la previsión de un vertiginoso crecimiento de la flota de vehículos, de 146 millones en 2014 a alrededor de 500 millones en 2040 (AlE, 2015; EIA, 2014; Huo y Wang, 2012). Se estima que, incluso con la utilización de técnicas de recuperación de petróleo mejorada y con el desarrollo de la producción de petróleo de formaciones compactas (tight oil), la producción de China de petróleo disminuirá a lo largo de las próximas décadas, porque sus principales campos petrolíferos están maduros y, por ende, su producción está en declive (AIE, 2015; EIA, 2014)․ . Así, las importaciones netas de ese combustible deberán alcanzar entre 12 millones y 14,5 millones de barriles diarios en 2040, cifra correspondiente a cerca del 70\% del consumo chino ese año (EIA, 2014; AIE, 2015; OPEP, 2015).

Entre las principales fuentes de abastecimiento de China (Oriente Medio, África, Comunidad de Estados Independientes (CEI) y América Latina), las latinoamericanas fueron las que más crecieron entre 2003 y 2015 (42\% al año). Prácticamente nulas en 2003, llegaron a alrededor de 854.000 barriles diarios en 2015 , correspondientes al $13 \%$ de las importaciones y al $8 \%$ del consumo chino. Cerca del $91 \%$ de esa cantidad se produjo en la República Bolivariana de Venezuela (38\%), el Brasil (33\%) y Colombia (21\%).

Mediante la diplomacia, China busca establecer lazos comerciales permanentes con otros países, tanto con respecto al petróleo como para el comercio en general. Sin embargo, como parte de su estrategia de desarrollo autónomo, recurre al mismo tiempo a dos instrumentos para garantizar el suministro de petróleo, a saber: inversiones directas, por empresas públicas de China, y financiamientos con pago en barriles de petróleo, por bancos públicos chinos. Se estima que el primer instrumento ha asegurado cerca de 1.900 millones de barriles de las reservas latinoamericanas ${ }^{9}$ y el segundo - considerando solo los contratos firmados en el período 2008-2011- cerca de 2.300 millones (totalizando cerca del 17\% de las reservas probadas en territorio chino).

La IED de China en el sector petrolero de América Latina llegó a la región con la inversión de la China National Petroleum Corporation (CNPC) en el Perú en 1994. Según Ortiz Velásquez (2016), además de la falta de divulgación de los valores, existen diversos problemas para medir las inversiones de China. Hecha esta salvedad, las cifras disponibles evidencian un proceso acelerado de acceso al petróleo mediante inversiones de China.

Entre 2001 y 2013, se realizaron al menos 23 proyectos de inversiones de China con el objetivo de acceder al petróleo latinoamericano, con un valor conocido de casi 33.000 millones de dólares (Rocha, 2016). Las cuatro grandes empresas estatales de petróleo de China (CNPC, China National Offshore Oil Corporation (CNOOC), China Petroleum and Chemical Corporation (Sinopec) y Sinochem Group) llegaron a América Latina en ese período. La mayor parte de esas inversiones, tanto en valor (25.400 millones de dólares) como en número (15), llegaron a América Latina entre 2010 y 2013, de manera que las inversiones de China en el sector petrolero de la región son un fenómeno reciente.

8 Si el precio del petróleo se mantiene bajo, las inversiones futuras de las grandes empresas petroleras estatales podrían resultar afectadas y reducir aún más la producción de China de petróleo a mediano y largo plazo (EIA, 2014 y 2015).

9 Esta estimación podría duplicarse con la comprobación de las reservas del campo de Libra y no incluye los campos MPE3 (Orimulsión) y Junín 10, localizados en la Faja del Orinoco (República Bolivariana de Venezuela), una de las mayores reservas de petróleo del mundo. 
Las empresas de China han preferido acceder al petróleo latinoamericano mediante la adquisición de los derechos sobre los campos de empresas ya establecidas en la región o adquiriendo las empresas que poseen esos derechos. Recientemente, comenzaron a invertir en proyectos más desafiantes desde el punto de vista tecnológico, incluidos los proyectos de aguas profundas como el campo petrolífero de Libra en el litoral brasileño.

Las reservas de esas empresas en la República Bolivariana de Venezuela, el Brasil, la Argentina y el Ecuador ascienden por lo menos a 750, 700, 284 y 140 millones de barriles, respectivamente. La producción de China de petróleo en suelo latinoamericano suma casi 400.000 barriles diarios (véase el cuadro 1). Esas empresas producen principalmente en la República Bolivariana de Venezuela (200.000 barriles diarios), seguida de la Argentina (50.000 barriles diarios), el Brasil (46.000 barriles diarios), el Ecuador (43.000 barriles diarios), Colombia (28.000 barriles diarios) y el Perú (20.000 barriles diarios). Cabe destacar que la CNPC tiene un proyecto para producir 1 millón de barriles diarios en la República Bolivariana de Venezuela con Petróleos de Venezuela, S.A. (PDVSA) ${ }^{10}$. Además, según la Agencia Nacional de Petróleo, Gas Natural y Biocombustibles (ANP, 2014), la producción del campo de Libra puede alcanzar 1,4 millones de barriles diarios, generando una producción equivalente de 140.000 barriles diarios, tanto para la CNPC como para la CNOOC en el Brasil. Por lo tanto, visto que las inversiones de China llegaron a América Latina recientemente (2010-2013), es probable que la producción de petróleo del país asiático en suelo latinoamericano aumente en los próximos años.

Cuadro 1

Estimación del petróleo latinoamericano bajo control chino

(inversión extranjera directa (IED) y préstamos) exportado y no exportado a China, alrededor de 2014-2015

(En miles de barriles diarios)

\begin{tabular}{lcrrrr}
\hline País & $\begin{array}{c}\text { Producción mediante } \\
\text { IED de China }\end{array}$ & $\begin{array}{c}\text { Pago por préstamos } \\
\text { de China }\end{array}$ & Total & $\begin{array}{c}\text { Enviado a China } \\
\text { (importaciones } \\
\text { de China) }\end{array}$ & No enviado a China \\
\hline Argentina & 50 & 0 & 50 & 6 & 141 \\
\hline Brasil & 46 & 200 & 246 & 15 & 105 \\
\hline Ecuador & 43 & 68 & 111 & 0 & 96 \\
\hline Perú & 19 & 0 & 600 & 277 & 323 \\
\hline $\begin{array}{l}\text { Venezuela (República } \\
\text { Bolivariana de) }\end{array}$ & 200 & 400 & 1026 & 439 & 586 \\
\hline Subtotal & 358 & 668 & 28 & 203 & 0 \\
\hline Colombia & 28 & 0 & 0 & 18 & 0 \\
\hline Otros & 0 & 0 & 28 & 221 & 0 \\
\hline Subtotal & 28 & 0 & 1053 & 660 & 586 \\
\hline Total & 386 & 668 & & & 0 \\
\hline
\end{tabular}

Fuente: Elaboración propia, sobre la base de F. F. Rocha, "Acesso chinês a recursos naturais na América Latina", Río de Janeiro, Instituto de Economía, Universidad Federal de Río de Janeiro (UFRJ), 2016.

Junto con la ampliación del comercio importador y de las inversiones directas, a partir de 2008 comenzaron a realizarse préstamos chinos con el pago en petróleo como contrapartida. La disponibilidad de datos confiables y desagregados sobre esta modalidad todavía es limitada y se concentra en el período 2008-2011, cuando se realizaron nueve acuerdos de ese tipo.

El país asiático firmó nueve contratos de ese tipo en tres países de la región: cuatro en la República Bolivariana de Venezuela, con PDVSA, por un total de 32.600 millones de dólares, que proporcionarán a China por lo menos 1.300 millones de barriles petróleo en 12 años; uno en el Brasil, con Petrobras, de 10.000 millones de dólares, que proporcionará 700 millones de barriles del combustible al país asiático en 10 años; y cuatro en el Ecuador, con EP Petroecuador (y el Ministerio de

10 Véase República Bolivariana de Venezuela (2014). 
Economía y Finanzas), por 5.000 millones de dólares, que se traducirán en por lo menos 300 millones de barriles para China en 10 años $^{11}$. Si esos volúmenes se suman a los asegurados por la IED de China, el país ya se aseguró cerca del 10\%, el 6\% y el 0,7\% de las reservas del Brasil, el Ecuador y la República Bolivariana de Venezuela, respectivamente.

Cabe señalar que este tipo de acuerdo asegura una cantidad de petróleo mayor de la necesaria para pagar el préstamo. En todos los casos sobre los que se dispone de datos, el tiempo necesario para alcanzar el valor inicial del préstamo (sin contabilizar los intereses) con pagos en petróleo es de menos de la mitad de la vigencia del acuerdo. En otras palabras, el petróleo no está sujeto a las adquisiciones de China simplemente para cancelar la deuda, pues hay cláusulas contractuales que destinan ventas a China que van más allá de esa quita.

Además de garantizar directamente el petróleo latinoamericano, los préstamos a cambio de petróleo actúan como mecanismo auxiliar facilitador del acceso. Existen varios acuerdos de cooperación firmados entre China y países latinoamericanos que resultaron de los préstamos chinos (Downs, 2011; Sanderson y Forsythe, 2012; Alves, 2013). Por ejemplo, en el Brasil, después del préstamo chino por petróleo de 2009 a Petrobras, Sinopec y la empresa brasileña también firmaron un acuerdo de cooperación estratégica, que garantizó a la empresa de China la participación en dos bloques de aguas profundas a lo largo de la costa nordeste brasileña.

Otra característica interesante es que el petróleo objeto de esas cláusulas puede dirigirse a la propia China o ser vendido por las empresas de China en otros países, una decisión que corresponde exclusivamente a las autoridades de ese país (Gobierno, bancos y empresas estatales). Además, según Jiang y Ding (2014), las empresas de China controlan en gran medida cómo y a quién venderán su producción proporcional resultante de la IED. Entre 2014 y 2015, las empresas de China controlaban, mediante préstamos por petróleo e inversiones, al menos 1,05 millones de barriles diarios de la producción de petróleo latinoamericano (el 11\% de la producción regional). Debido al tipo de petróleo latinoamericano (pesado e inadecuado para las refinerías de China, dedicadas al petróleo liviano) ${ }^{12}$ y a los elevados costos de transporte hasta China, se ha preferido la venta a los Estados Unidos o la propia América Latina ${ }^{13}$. Como dijo el ex Ministro de Comercio e Industria de la República Bolivariana de Venezuela, Moisés Naim, "es una locura abastecer a China desde Venezuela" (Sanderson y Forsythe, 2012). Con los recursos de la venta, las empresas de China adquieren petróleo en Oriente Medio y en otras regiones más próximas a China, donde este tiene características más compatibles con su capacidad de refinación. Así, todo indica que las empresas y los bancos chinos están compatibilizando sus estrategias de maximización de ganancias con las políticas de seguridad energética estipuladas por el Gobierno de su país.

La prioridad de China es garantizar la propiedad del petróleo y la posibilidad de enviarlo directamente al país cuando se considere necesario. En el cuadro 1 se muestra que, en 2014-2015, solo fue necesario enviar a China menos de la mitad de los más de 1.000 barriles diarios bajo control chino (producidos mediante IED de China o apropiados como pago por préstamos). De enviarse todo ese petróleo, correspondería a cerca del 20\% de las importaciones de China en 2014. Cabe señalar que están en curso o en planificación inversiones que permitirán la reducción de las restricciones económicas a las importaciones desde América Latina, como el canal interoceánico de Nicaragua y una refinería en territorio chino para tratar el petróleo superpesado de la República Bolivariana de Venezuela (EIA, 2015; Ray, Gallagher y Sarmiento, 2016).

\footnotetext{
${ }^{11}$ Recientemente se han firmado o negociado otros acuerdos de este tipo. Por ejemplo, en 2013, China prestó 5.000 millones de dólares a la República Bolivariana de Venezuela contra el envío de 100.000 barriles diarios de petróleo a China por tres años (Gallagher y Myers, 2014) y en 2015 se realizaron nuevos préstamos por petróleo en el Brasil y la República Bolivariana de Venezuela (Myers, Gallagher y Yuan, 2016). Además, en 2017 se ha firmado un contrato por 5.000 millones de dólares entre Petrobrás y China Development Bank (CDB), contra el pago de 100 mil barriles/día de petróleo durante 10 años (PETROBRAS, 2016 y 2017).

12 Véanse Altomonte (2013), Winter y otros (2013), Rosen y Houser (2007), Koch-Weser (2015) y Jiang y Sinton (2011).

13 Véanse Winter y otros (2013) y Koch-Weser (2015).
} 
En el cuadro 1, llaman la atención el escaso control chino sobre el petróleo de Colombia y la inexistencia de negocios petroleros chinos en México, dos de los cuatro mayores países productores de la región, junto con la República Bolivariana de Venezuela y el Brasil. Esto puede indicar que los dos países se confirman como áreas sometidas a la influencia geopolítica de los Estados Unidos.

Estos procedimientos muestran que las autoridades de Beijing consideran que, por ser de extremo interés nacional y fundamental para la seguridad económica, no se debe confiar la búsqueda de recursos naturales al libre mercado. De acuerdo con Downs (2011), si bien el China Develpment Bank (CDB), principal financiador chino en América Latina, tiene una autonomía considerable, no es un actor totalmente independiente, pues todos sus proyectos internacionales requieren la aprobación del Consejo de Estado chino. Además, a pesar de las reformas realizadas para dar más autonomía operativa a las empresas petroleras estatales, que pueden definir tácticas y objetivos para adquisiciones globales, esto no significó autonomía estratégica, pues las metas principales son establecidas por el Gobierno (Corrêa, 2015). El control se realiza mediante la indicación, de forma directa o indirecta, por el Partido Comunista chino de las personas que ocuparán los principales cargos de esas empresas (Jiang y Sinton, 2011; Corrêa, 2015).

\section{El acceso chino al mineral de hierro $\mathrm{y}$ al cobre latinoamericanos}

En las últimas décadas, el proceso de industrialización, urbanización y mejoramiento de la infraestructura se tradujo en un rápido aumento de la demanda de China de metales, incluidos el cobre, el aluminio y el hierro (Coates y Luu, 2012). En China, el consumo aparente de mineral de hierro aumentó de 118 millones de toneladas finas en 2000 a 872 millones en 2014, mientras el consumo de cobre refinado aumentó de 1,9 millones de toneladas en 2000 a 10,9 millones de toneladas en 2014.

Se estima que el consumo de diversos metales continuará siendo elevado y que la producción de varios minerales metálicos no aumentará de forma significativa, de manera que el país asiático continuará dependiendo en gran medida de las importaciones de minerales en los próximos años. Según el Banco Mundial (2014), la tasa de urbanización de China aumentará del actual 54\% a cerca del 70\% en 2030. Esto significa que el país asiático albergará aproximadamente a 300 millones de personas en las ciudades a lo largo de los próximos años, proceso que demandará metal para la construcción de infraestructura. Además, Berkelmans y Wang (2012) afirman que los edificios chinos requerirán más metal por metro cuadrado pues, debido a la elevada densidad poblacional, son cada vez más altos y el gran incremento previsto en el número de automóviles - que por sí solo aumentará el consumo de metales - estimulará la demanda de edificios con grandes garajes subterráneos.

Debido a la escasa disponibilidad interna de chatarra (Holloway, Roberts y Rush, 2010; Zhang y otros, 2015), la producción de China de metales todavía será muy intensiva en el consumo de minerales en los próximos años. A su vez, la oferta interna de diversos minerales metálicos se mantendrá baja en relación con la demanda, pues la relación reserva-producción es baja, de manera que - de no descubrirse grandes yacimientos - no existe mucho margen para un aumento significativo de la producción. Asimismo, según el Banco Mundial (2016), el precio del mineral de hierro continuará bajo hasta por lo menos 2020, de manera que diversos productores chinos no lograrán mantener la rentabilidad (debido a su elevado costo) y cesarán la producción (Carvalho y otros, 2014).

América Latina es relevante para China en el suministro de diversos minerales metálicos. Por ejemplo, en 2014, la participación de la región en las importaciones de China de mineral de hierro, de cobre, de plata, de cinc, de plomo, de molibdeno y de tungsteno fue, respectivamente, del $21 \%$, el $50 \%$, el $41 \%$, el $32 \%$, el $12 \%$, el $51 \%$ y el $14 \%$. Sin embargo, mientras el déficit de mineral de hierro 
y de cobre fue, respectivamente, de 21.000 millones y 11.000 millones de dólares en 2014, el déficit chino de todos los demás minerales metálicos de la región sumó solo 2.000 millones de dólares en 2014. Así, este estudio se limita a los casos del mineral de hierro, el mineral de cobre y el cobre refinado.

América Latina es la segunda región de origen de las importaciones de China de mineral de hierro (el 23\% en 2015), después de Oceanía. Las importaciones de China del mineral latinoamericano aumentaron de 17 millones de toneladas en 2000 a casi 220 millones en 2015, de los cuales 192 millones de toneladas se produjeron en el Brasil, 11 millones de toneladas en el Perú, 10 millones de toneladas en Chile y 5 millones de toneladas en otros países latinoamericanos. En la actualidad, esos tres países representan el 98\% de las importaciones de China de mineral de hierro con origen en América Latina.

Cabe destacar que, tras la crisis de 2008, el aumento de la importación de China del mineral de hierro latinoamericano también se debió a una estrategia de la empresa minera Vale, actualmente responsable del $80 \%$ de la importación de China del mineral de origen latinoamericano. Con la crisis de 2008, Europa y el Japón, que eran sus principales compradores, redujeron drásticamente su demanda, motivando el redireccionamiento de sus exportaciones al mercado chino (Vale, 2013). Además, los tratados de libre comercio entre China y Chile (2006) y China y el Perú (2010), cuyo principal objetivo era garantizar el acceso chino a los minerales metálicos (Roldán y otros, 2016), facilitaron el aumento del comercio de minerales entre la región y el país asiático.

Con respecto al cobre, América Latina es claramente la principal región de origen de las importaciones de China del metal, pues pasó del 20\% a mediados de la década de 1990 a casi el $50 \%$ en 2015. Los volúmenes importados desde América Latina aumentaron de menos de 100.000 toneladas finas de cobre a mediados de la década de 1990 a más de 3,5 millones de toneladas en 2015. En América Latina, China importa el metal básicamente desde Chile (el 66\% en 2015) y el Perú (24,5\%), seguidos de México (6\%) y el Brasil (3\%).

Es interesante notar que la región latinoamericana es aún más importante para China de lo que muestran los datos sobre comercio, pues el cobre extraído en la región también es comprado por otros países que refinan el metal y lo exportan al territorio chino. Por ejemplo, la India, el Japón y la República de Corea son importantes proveedores de cobre refinado para China ${ }^{14}$. Sin embargo, debido a que su producción del metal refinado se basa sobre todo en la refinación primaria y esos países no producen el mineral en cantidades significativas, su producción de cobre refinado supone la importación del mineral adquirido mayoritariamente en América Latina (más del 60\% en 2014). Se puede estimar que, en 2014, 400.000 toneladas finas de mineral de cobre latinoamericano (o el 6\% de las importaciones de China de cobre en 2014) fueron importadas de forma indirecta por China a través de esos tres países.

La IED de China en metales recién llegó a la región a mediados de la década de 2000 y por eso tuvo, hasta ahora, una importancia relativamente menor en el acceso de ese país a los minerales metálicos latinoamericanos. Hay, sin embargo, fuertes razones para suponer que dichas inversiones ya aseguraron una cantidad significativa de mineral de hierro y mineral de cobre latinoamericanos para China, a la que accederá a lo largo de los próximos años (Rocha, 2016).

Como reflejo del sector minero chino, la mayoría de las empresas que llegaron a la región son estatales, no obstante empresas privadas e híbridas también hayan llegado a América Latina. Esas empresas prefieren acceder a los minerales metálicos latinoamericanos mediante la adquisición mayoritaria de los derechos sobre las minas de empresas ya establecidas en la región o de las empresas que poseen esos derechos y, además, sobre las minas que ya se encuentran en fase avanzada de explotación y de cantificación técnica de las reservas (Roldán y otros, 2016).

En el período 2006-2014, se realizaron 16 inversiones en el sector latinoamericano de minería de hierro y de cobre, por un valor conocido de casi 11.000 millones de dólares (Rocha, 2016). El Perú fue, en absoluto, el país latinoamericano que recibió el mayor número de proyectos y el mayor importe

\footnotetext{
${ }^{14}$ En 2014, esos tres países suministraron el 10\% de las importaciones de China de cobre (mineral de cobre y cobre refinado).
} 
financiero. Según González-Vicente (2013), esto se debe sobre todo a la relación comercial ya existente entre el Perú y China (proporcionada por la inversión de Shougang Group en 1992), a su sistema sumamente liberal en materia de inversiones en la minería y a su disponibilidad de recursos primarios.

Shougang Group produce actualmente 7,3 millones de toneladas finas de mineral de hierro por año y posee el derecho sobre 764 millones de toneladas finas de las reservas peruanas. Este volumen equivale a aproximadamente el $11 \%$ de las reservas existentes en territorio chino. Hasta 2015, la única otra empresa de China dedicada al mineral de hierro en la región era Wuhan Iron and Steel Corporation en el Brasil, cuya producción - a través de una pequeña participación del 10,5\% en MMX Mineração e Metálicos - alcanzaba solamente a 180.000 toneladas finas. Sin embargo, se estima que el acceso garantizado aumentará en el futuro, a medida que las minas de Pampa de Pongo (Nanjinzhao) en el Perú, Vale do Rio Pardo (Honbridge Holdings) en el Brasil y Oso Negro (Hebei Wenfeng) en Chile se desarrollen y sus recursos se clasifiquen como reservas. De esa forma, si en 2014-2015 la producción de China de mineral de hierro en América Latina era de cerca de 7,5 millones de toneladas finas (equivalentes al 5,4\% de las importaciones de China del mineral de origen latinoamericano en 2015), con la entrada en operación de los tres proyectos (y con la expansión de la producción de Marcona por Shougang) esa producción debería crecer casi 30 millones de toneladas finas, aumentando a más de 35 millones (Rocha, 2016).

En relación con el cobre, las reservas latinoamericanas en poder de los chinos son de 20,7 millones de toneladas finas, que equivalen al $70 \%$ de las reservas en territorio chino. Esa cantidad no incluye otro volumen potencialmente elevado que ha de determinarse en los proyectos de minería bajo el control de empresas de China: El Galeno (Perú), Don Javier-Cercana (Perú), Panantza-San Carlos (Ecuador), Taltal (Chile) y La Plata (Chile). De las reservas conocidas, 17 millones de toneladas finas están localizadas en el Perú (el 21\% de las reservas peruanas), 3,5 millones en el Ecuador y 0,27 millones en el Estado Plurinacional de Bolivia.

Las únicas empresas de China que producen mineral de cobre en suelo latinoamericano son Aluminum Corporation of China Limited (Chinalco) y el consorcio China Minmetals Corporation, Suzhou Guoxin y China International Trust and Investment Company (CITIC) (Minera Las Bambas), dos emprendimientos muy recientes en el Perú. Al considerar que la producción de Chinalco comenzó a mediados de 2014 y la Minera Las Bambas entró en operación recién en diciembre de 2015, cabe suponer que la producción de las empresas de China, de 190.000 toneladas finas de mineral de cobre en 2015 (el 11\% de la producción peruana), se debe estar ampliando bastante a partir de 2016.

La producción de China de mineral de cobre en América Latina aseguró hasta ahora apenas el equivalente al 5,3\% de sus importaciones de origen latinoamericano en 2015 . No obstante, se estima que solamente en el Perú esta aumentará más de 1 millón de toneladas finas hasta 2021, alcanzando cerca de 1,2 millones (Rocha, 2016), volumen que corresponde a cerca de dos tercios de la producción actual de mineral de cobre en China (1,76 millones de toneladas finas en 2014).

\section{El acceso chino a la soja latinoamericana}

El acelerado crecimiento económico chino ha sido acompañado de grandes cambios en la dieta, tanto con respecto a la cantidad de alimentos consumida como a su composición. Debido a que la elasticidad-ingreso de la demanda de proteína animal en China es elevada, el crecimiento del ingreso determinó que el consumo de ese alimento (principalmente carne) aumentara rápidamente (Ghose, 2014; Xing y Goldsmith, 2013). A su vez, como el país asiático es básicamente autosuficiente en la producción de carne y salvado de soja, el aumento de la demanda de proteína animal impulsó la demanda de China de granos de soja. Así, el consumo chino de la oleaginosa aumentó de cerca de 10 millones a 83 millones de toneladas entre el inicio de la década de 1990 y 2014. 
Westcott y Hansen (2016) estiman que las importaciones de China de la oleaginosa llegarán a más de 100 millones de toneladas a comienzos de 2020. Aunque se prevé que la expansión del consumo de productos de origen animal disminuirá (Xing y Goldsmith, 2013), la demanda de salvado de soja aumentará todavía durante mucho tiempo y, con ella, la demanda de granos de soja ${ }^{15}$.

Con respecto a la oferta interna de soja, se estima que el aumento de la urbanización y la industrialización de China reducirán la tierra arable disponible, disminuyendo el área para el cultivo (Ghose, 2014), un proceso acentuado por la contaminación del agua y del suelo. A ello se suma que las políticas gubernamentales favorecen la producción de cereales y la vuelven más rentable con respecto a la producción de soja, de manera que el área de cultivo de la oleaginosa no debería aumentar. Además, la falta de acceso de los productores chinos de soja a la tecnología de semillas más reciente, la pequeña escala de las fincas y las prácticas agronómicas inadecuadas dificultan el aumento de la productividad de la tierra, que está estancada desde mediados de la década de 1990 (Clever y Xinping, 2016).

Las importaciones de soja latinoamericana por China han crecido desde 1996 y, desde 2000, representan una media de casi el $60 \%$ de las importaciones de China de la oleaginosa (el $40 \%$ restante proviene de América del Norte). Esto significa que los países latinoamericanos suministran casi la mitad del consumo chino de granos de soja. Con respecto a la concentración de la producción, China importa la oleaginosa principalmente del Brasil (el 77\% en 2015), la Argentina (18\%) y, más recientemente, también del Uruguay (5\%).

Al contrario de las noticias divulgadas por los medios de comunicación, China no está accediendo de forma significativa a la soja de la región latinoamericana mediante la IED en acaparamiento de tierras (land grabbing). Lejos de eso, para definir su estrategia se inspiró en las grandes empresas mercantiles transnacionales, que controlan toda la cadena productiva de la soja (excepto el cultivo). La clave de la estrategia ha sido adquirir empresas que ya poseen una infraestructura logística en la región para la comercialización de la soja.

De hecho, según la literatura reciente (Hofman y Ho, 2012; Myers y Jie, 2015; Oliveira, 2015), si bien los medios de comunicación informaron de diversas inversiones de China con el objetivo de adquirir tierras para plantío, la mayoría no se concluyó o no pasó de un rumor. El país asiático intentó realizar ese tipo de inversión para acceder a la soja, pero los inversionistas fueron bloqueados por restricciones impuestas a la compra de tierras por extranjeros en el Brasil (2010) y la Argentina (2011).

Autores como Myers y Jie (2015), Oliveira (2015) y Hofman y Ho (2012) coinciden en afirmar que, en América Latina, la preocupación sobre las inversiones para el acaparamiento de tierras está mal dirigida cuando se refiere a las empresas de China, pues la gran mayoría de esas inversiones corresponde a empresas de los Estados Unidos, Europa, la Argentina y el Japón. Oliveira (2015) ofrece una interesante explicación para la preocupación exagerada en el Brasil, al afirmar que existe una alianza entre latifundistas brasileños, propietarios de industrias, economistas de libre mercado y abogados, que hacen un uso estratégico de los medios de comunicación para generar miedo y restricciones que afecten en forma desproporcionada a los inversionistas chinos (en tierras) en el Brasil, de manera de posicionarse como socios necesarios para las inversiones de China (y también de empresas de otras nacionalidades). El autor observa que las cuatro grandes empresas comercializadoras de materias primas mencionadas con anterioridad (es decir, Archer Daniels Midland (ADM), Bunge, Cargill y Louis Dreyfus, conocidas como las $\mathrm{ABCD}$ ) también recurren a ese uso estratégico de los medios de comunicación para desviar la atención del importantísimo papel que ejercen sobre las inversiones en tierras alrededor del mundo y, simultáneamente, para oponerse al aumento de la competencia de China en la agroindustria internacional.

\footnotetext{
15 Según Xing y Goldsmith (2013), el consumo chino de salvado será de casi 70 millones de toneladas en 2020 y de más de 100 millones de toneladas en 2030. Si se supone que el $80 \%$ de la soja consumida en el país asiático se procesa (tritura) y que 1 tonelada de la oleaginosa genera 0,78 toneladas de salvado, la demanda de granos de soja aumentará de 83 millones de toneladas en 2014 a aproximadamente 112 millones y 165 millones de toneladas en 2020 y 2030, respectivamente.
} 
Solamente se confirmaron dos inversiones realizadas por empresas de capital chino con el objetivo de adquirir tierras para acceder a la soja latinoamericana ${ }^{16}$. En 2007, la sociedad entre Zhejiang Fudi Agriculture Group y el Departamento de Agricultura de la provincia de Heilongjiang compró 16.800 hectáreas de tierras brasileñas (7.000 hectáreas en Rio Grande do Sul y 16.100 en Tocantins) por 48,6 millones de dólares (Myers y Jie, 2015; Oliveira, 2015). La intención inicial era adquirir experiencia para después comprar más tierras en el Brasil, producir su propia soja en el país y exportarla a China. Sin embargo, debido a problemas administrativos y operativos, Zhejiang Fudi Agriculture Group vendió su participación mayoritaria a Chongqing Grain Group (CGG) (otra empresa de China) en 2011. La segunda inversión confirmada fue la de CGG al final de la década de 2000, cuando la empresa adquirió una finca de 52.000 hectáreas en el oeste de Bahía, en un terreno de calidad inferior que todavía no estaba preparado para la producción de soja (Oliveira, 2015). Cabe destacar que, por lo menos hasta inicios de 2014, este proyecto estaba lejos de entrar en operación (REUTERS, 2014).

Para entender la estrategia de China para asegurar la soja latinoamericana en el contexto de restricciones a la compra de tierras por extranjeros en la región, es necesario tener en cuenta el mercado de la oleaginosa entre América Latina y el país asiático. De acuerdo con Wesz Junior (2011 y 2014), debido a los procesos de verticalización y horizontalización de la cadena productiva en las últimas dos décadas, el mercado de la soja en América Latina está controlado principalmente por las cuatro grandes empresas mercantiles (ABCD). Esas empresas controlan desde el financiamiento, la provisión de insumos y la asistencia técnica hasta la comercialización de la producción (compra de grano, almacenamiento, industrialización, exportación y ventas en el mercado interno).

En el Brasil, esas empresas proporcionan financiamiento a los productores de soja mediante la compra anticipada de la producción. En muchos casos, el adelanto se realiza mediante la entrega de insumos por la cadena productiva bajo su propiedad. En otros, cuando el adelanto se realiza en dinero, los productores adquieren los insumos (fertilizantes, pesticidas, semillas, entre otros) de la misma empresa que los financió. Así, es la empresa mercantil, que posee su propia capacidad logística (almacenamiento, canales para comercializar la producción, puertos para exportación) y de procesamiento, que decidirá la manera en que comercializará los granos (mercado interno o exportación, granos o salvado-aceite). Este tipo de negociación utilizado por las empresas para adquirir la materia prima fomenta una gran dependencia de los productores de las empresas mercantiles, pues un único actor se convierte en el agente financiador, el proveedor de insumos, el órgano de asistencia técnica y el comprador de la producción responsable de la comercialización (Wesz Junior, 2011).

En América del Sur, incluso antes de la temporada de siembra, los pequeños agricultores menos capitalizados pueden comprometer hasta dos tercios de su cosecha a través de ese tipo de financiamiento, mientras los grandes agricultores más capitalizados frecuentemente comprometen un cuarto de su producción (Oliveira y Hecht, 2016, citado en Wesz Junior, 2016). En la Argentina, el sector de industrialización y exportación de la soja también está concentrado en muy pocas empresas, de las cuales las ABCD son las más importantes. De acuerdo con Wesz Junior (2014), esas empresas controlan entre el $70 \%$ y el $80 \%$ de las exportaciones de granos de soja del Brasil y la Argentina.

Las empresas ABCD tienen una considerable capacidad de procesamiento de la oleaginosa en China (Peine, 2013; Sharma, 2014). Así, al controlar la comercialización de la soja en América Latina,

\footnotetext{
${ }^{16}$ La compra por Pengxin Group de 12.500 hectáreas de tierra en Santa Cruz (Estado Plurinacional de Bolivia) por 27,2 millones de dólares (Myers y Jie, 2015) puede considerarse como una tercera inversión, aunque, según el sitio web de la empresa, la finca ya está en funcionamiento (soja, maíz y sorgo) pero ninguna cantidad de la oleaginosa boliviana ha sido importada por el país asiático (o exportada por el Estado Plurinacional de Bolivia a ese país). Otros ejemplos de IED incluyen inversiones para abrir oficinas o entrar en el sector (o adquirir fertilizantes) y la inversión de Pacific Century Group para la compra en el Brasil de activos de AIG en CalyxAgro en 2010. Pacific Century Group es una empresa con sede en Hong Kong y, según Oliveira (2015), es imposible saber cuánto capital chino posee en comparación con capitales de otras nacionalidades.
} 
se valen de su capacidad de logística para comercializar y exportar la oleaginosa a sus propias industrias de procesamiento en el país asiático, transformando la soja en salvado o aceite y vendiendo al mercado chino.

La estrategia de China para acceder a la soja latinoamericana debe analizarse en este contexto. La compra de tierra sin inversiones en logística para la comercialización y la exportación de la producción volvería a China dependiente de las grandes empresas transnacionales. Por esa razón, y como explica Oliveira (2015), la empresa de China Sanhe Hopeful solamente estaría interesada en financiar la producción de soja después de establecerse como un operador de terminal de granos, adquiriendo o construyendo sus propios almacenes en la región, a fin de exportar la soja comprada directamente a los productores brasileños para abastecer sus instalaciones de procesamiento en China.

En resumen, las restricciones a la compra de tierras por extranjeros solo reforzaron la tendencia natural de China a una estrategia de control de la logística y la infraestructura de la soja. Esto explica, por ejemplo, que en 2014 el CDB y el Industrial and Commercial Bank of China (ICBC) hayan prestado 2.100 millones de dólares a Belgrano Cargas y Logística para la restauración y el mejoramiento de la red ferroviaria de la Argentina (Wilkinson, Wesz Junior y Lopane, 2015; Gallagher y Myers, 2014). En 2010, Sanhe Hopeful adquirió el 20\% del proyecto de construcción de una nueva terminal de granos en el estado de Santa Catarina (Oliveira, 2015) ${ }^{17}$. También existe una propuesta de China para crear una ferrovía transoceánica, que conecte el océano Atlántico en el Brasil con el océano Pacífico en el Perú, posiblemente pasando por el Estado Plurinacional de Bolivia (Ray, Gallagher y Sarmiento, 2016). Este proyecto tiene el objetivo de conectar los puertos del Perú orientados al Pacífico con la nueva frontera de la soja del Brasil.

La entrada más significativa de capital agroindustrial chino en el complejo de la soja latinoamericana ocurrió mediante una adquisición negociada fuera de la región, pero que la tenía como principal objetivo (Oliveira, 2015). En 2014, la empresa estatal China National Cereals, Oils and Foodstuffs Corporation (COFCO) compró el 51\% de Nidera (1.200 millones de dólares) y de Noble Agri (1.500 millones de dólares) (Wilkinson, Wesz Junior y Lopane, 2015). En diciembre de 2015, COFCO adquirió el 49\% restante de Noble Agri (750 millones de dólares), quedándose con el 100\% de las acciones de la empresa. Esas inversiones evitan los desafíos enfrentados por las inversiones de China de tipo totalmente nuevo (greenfield) en el complejo de la soja en América Latina, en particular aquellos relacionados con la burocracia para el establecimiento de las empresas en la región, la adquisición de tierras y la concesión de licencias ambientales.

El objetivo de COFCO al adquirir esas empresas no es operar como una productora o una procesadora de soja en sí, sino como una empresa mercantil (Oliveira, 2015). En 2011, el presidente de la empresa de China afirmó que las empresas ABCD ofrecen un buen ejemplo para COFCO, dada su exitosa participación en toda la cadena de suministro de la industria (Myers y Jie, 2015). Explicó que dichas empresas no están involucradas en la producción agrícola sino que obtienen las cosechas de agricultores locales y proporcionan servicios e infraestructura.

Noble está presente en el Brasil, la Argentina, el Uruguay y el Paraguay, en los sectores de la soja, el café, la caña de azúcar, el biodiésel y el algodón. En el complejo de la soja, la empresa presenta una infraestructura logística bastante desarrollada, considerable capacidad de almacenamiento, unidades de procesamiento de la oleaginosa y presencia en las actividades de las fases iniciales de la cadena de producción (upstream), proporcionando fertilizantes, asistencia técnica y financiamiento, de manera similar a otros comerciantes globales. Para tener una idea de la importancia de esta empresa en la

\footnotetext{
17 Según Oliveira (2015), el proyecto ha enfrentado una considerable oposición por motivos sociales y ambientales y, a inicios de 2015, la construcción no se había iniciado debido a que la licencia ambiental y el decreto de utilidad pública todavía estaban pendientes.
} 
región, en la actualidad es responsable de aproximadamente el 10\% de las exportaciones de granos de soja de la Argentina, el $5 \%$ de las exportaciones de salvado y el $7 \%$ de las exportaciones de aceite, además de haber exportado, en 2014, el equivalente a 3.000 millones de dólares (FOB) en la región (Brasil, Argentina y Paraguay) (CIARA, s/f; Wilkinson, Wesz Junior y Lopane, 2015).

La otra empresa adquirida por COFCO, Nidera, también cuenta con una infraestructura logística bastante desarrollada en el complejo latinoamericano de la soja. Está presente sobre todo en el Brasil y la Argentina y, en menor medida, en el Uruguay (oficina y almacén) y el Paraguay (oficina). Esa presencia incluye terminales de granos y fertilizantes y considerable capacidad de almacenamiento. Actúa también en el procesamiento de la soja, en la producción y la comercialización de semillas, en la distribución de insumos (fertilizantes, pesticidas, entre otros) y en el financiamiento a los productores, además de comprar, almacenar y comercializar cereales y oleaginosas. Al igual que Noble, Nidera es un importante exportador de soja en la región. Por ejemplo, actualmente la empresa es responsable del $5 \%$ de las exportaciones de granos de soja de la Argentina, el $7 \%$ de las exportaciones de salvado y el 9\% de las exportaciones de aceite y, en 2014, exportó más de 3.500 millones de dólares (FOB) en la región (Brasil, Argentina) (CIARA, s/f; Wilkinson, Wesz Junior y Lopane, 2015).

En resumen, con esas dos adquisiciones, COFCO participa en actividades de financiamiento, provisión de insumos, asistencia técnica y comercialización de la producción en América Latina y en el procesamiento de la oleaginosa en salvado o aceite en China. Mediante esa estrategia logró evitar los problemas enfrentados por las inversiones anteriores y, al mismo tiempo, disminuyó la dependencia del país asiático de las empresas transnacionales. La empresa estableció una presencia sólida en el complejo de la soja del Cono Sur, donde su participación en el ramo de las semillas puede ofrecer ventajas con respecto a las empresas ABCD (Wilkinson, Wesz Junior y Lopane, 2015).

Por último, cabe señalar que hay una gran vía de acceso a la soja brasileña que, por falta de información, no fue posible abordar en el presente trabajo. Se trata de la vía del arrendamiento de tierras productoras de soja por fondos de inversión extranjeros, modalidad que ya puede estar empleándose en América Latina para evitar el problema de las restricciones a la adquisición de tierras. El hecho de que la IED de China se esté orientando a la logística de comercialización y exportación de soja permite la difusión de capitales chinos en los negocios de la soja por esa vía de arrendamiento "disfrazado". En palabras de un especialista:

Así, la presencia más fuerte de capital extranjero en la producción de soja en el Brasil proviene de empresas especializadas en gestión agrícola y pools de siembra que canalizan múltiples fuentes de capital hacia el sector. Todavía no se ha realizado una investigación más cuidadosa de esas fuentes de capital y no caben dudas de que algunos capitales chinos de hecho se canalizaron hacia la producción de soja en el Brasil por ese medio, en particular mediante la participación de Pacific Century Group en CalyxAgro (Oliveira, 2015).

\section{A modo de conclusión}

La dinámica del crecimiento chino a largo plazo depende, entre otros factores, del acceso a materias primas a escala mundial. Dada la escasez relativa en China, la garantía de fuentes externas de suministro a largo plazo es uno de los objetivos centrales del Gobierno, que impulsa una ofensiva diplomática mundial con el objetivo de diversificar las fuentes de importación (Medeiros, 2008). La estrategia Going Global, lanzada por el Gobierno chino a comienzos de la década de 2000, está motivada sobre todo por razones de seguridad y autonomía nacional, pero también tiene el objetivo de modificar los términos de intercambio: China ha vendido barato sus productos industriales para conquistar el mercado internacional y ha comprado caro las materias primas que necesita en volúmenes que crecen en forma acelerada. 
En el presente artículo, orientado a una necesaria evaluación del papel de China en la reconfiguración en curso de las relaciones "centro-periferia" a las que América Latina se ha subordinado históricamente, se describió y analizó la búsqueda de petróleo, metales (hierro y cobre) y soja realizada por China en la región. A esos productos corresponde actualmente más del $70 \%$ de las importaciones del país desde América Latina. La búsqueda obedece a la demanda derivada del acelerado crecimiento chino y está orientada por una planificación a largo plazo que, ante la abundancia latinoamericana, considera a la región como una gran proveedora de recursos naturales.

Se mostró la manera en que, en el caso del petróleo, el acceso tiene lugar principalmente mediante financiamientos en cambio de petróleo e inversiones directas, mientras que en el caso del hierro y el cobre este se obtiene mediante inversiones directas e importaciones en general. En estos casos, la manera elegida por China para garantizar la seguridad en el abastecimiento parece ser el control físico del recurso. En el caso de la soja, en forma pragmática, el camino elegido han sido las importaciones cada vez más intermediadas por empresas mercantiles ya presentes en la región y recientemente adquiridas por China. Otra vía posible, sobre la cual existe poca información, puede ser el arrendamiento de tierras por fondos de inversión con participación de China, que sería una forma de evitar las limitaciones a la compra de tierras por extranjeros. Las inversiones en infraestructura de acceso a recursos naturales en general - todavía embrionarias y por eso no abordadas en este artículo - también pueden llegar a movilizar voluminosos recursos chinos.

En forma similar a lo que ocurrió durante varios siglos de su historia, América Latina se beneficia del comercio de materias primas de distintas maneras: además de generar ingresos y empleo, se obtienen muchas divisas extranjeras, necesarias para la expansión de sus economías. Como ya se dijo más de una vez, los recursos naturales no son, en principio, un "castigo de Dios". Sin embargo, y como se destaca en la literatura reciente sobre la "maldición de los recursos naturales", las tendencias actuales en las relaciones con China (y Asia en general) no parecen en absoluto tan prometedoras para América Latina como podrían ser si los países de la región, individual o colectivamente, tuvieran una estrategia para maximizar los beneficios potenciales ofrecidos por la abundancia de recursos naturales. América Latina carece de una estrategia de desarrollo a largo plazo que armonice los intereses chinos con metas de progreso económico y social más ambiciosas que las que están orientando a los Gobiernos de la región.

Hay por lo menos cinco aspectos relativos a la recepción de capitales extranjeros en América Latina, y en particular de los intereses chinos en los recursos naturales, a los que se debería prestar mucha atención, en la dirección de lo que la CEPAL denomina "nueva gobernanza de los recursos naturales" (CEPAL, 2014; Bárcena y Prado, 2016; Altomonte y Sánchez, 2016).

El primero es que, mientras en la propia China se incentiva al capital extranjero a entrar en sociedad con capitales locales y se lo somete a una serie de contrapartidas que benefician la ampliación del valor agregado y el progreso técnico local, América Latina es un espacio libre para adquisiciones de China sin mayores exigencias.

El segundo aspecto es que la elevada rentabilidad obtenida en las exportaciones de productos primarios no siempre se somete adecuadamente a impuestos o esto se hace en forma precaria, tanto en el caso de capitales nacionales como extranjeros y, en consecuencia, no siempre se traducen en un beneficio para la población local.

El tercero reside en que la explotación de productos primarios tiende a ser poco intensiva en mano de obra e, incluso en el caso de la soja y otros alimentos, la imagen que se proyecta es la de la vieja actividad de "enclave minero", sin la promoción de encadenamientos productivos ni progreso técnico a nivel local. Se observa una genuina preocupación por la "reprimarización" de las economías latinoamericanas, acentuada porque el progreso técnico encabezado por la industria de transformación en los países desarrollados deja a la región al margen de la capacidad mundial de generación y difusión de tecnología. 
El cuarto consiste en que el problema anterior se acentúa por las excesivas apreciaciones cambiarias. En períodos de aumento de los precios de los productos básicos, la política macroeconómica debería evitar apreciaciones cambiarias que conspiren contra las inversiones en la producción industrial, prestando especial atención a la influencia de los flujos de capital de corto plazo en el cambio, que suelen acompañar esos períodos de bonanza y generar o acentuar crisis externas cuando la bonanza termina.

Por último, y no menos importante, la fuerte ampliación de la explotación de recursos naturales suscitada por la demanda de China no se ha acompañado con los debidos cuidados ambientales, con consecuencias negativas tanto para el planeta como para las poblaciones locales.

Por cierto, la adopción por los países latinoamericanos de estrategias nacionales -como las de China y los Estados Unidos - o nacionales y regionales - como las de los países europeos - les permitiría obtener, ante las necesidades de China, beneficios muy superiores a los obtenidos hasta ahora. Sería mejor aún si la estrategia se adoptara de común acuerdo entre los países de la región, transformándola en una estrategia regional integrada.

Como parte de esta, cabría también a los países latinoamericanos definir un equilibrio entre los intereses nacionales-regionales y mundiales, evitando transformarse en palco de disputas internacionales que no los beneficien. Hasta ahora la región ha sido, en la geopolítica global, un área de influencia inicialmente europea y, posteriormente, estadounidense. La velocidad sin precedentes de la embestida de China en la región puede ser cuestionada por los occidentales y, en particular, por los estadounidenses, como muestran algunas indicaciones ya registradas en ese sentido. No sin razón, esa pregunta, no abordada en el presente artículo, inquieta a un número cada vez mayor de estudiosos de las relaciones entre los Estados Unidos y China en lo que se refiere a América Latina, especialmente a partir del acuerdo entre el Brasil, la Federación de Rusia, la India, China y Sudáfrica, el denominado grupo BRICS (Paz, 2012; Nolte, 2013).

\section{Bibliografía}

AlE (Agencia Internacional de la Energía) (2015), World Energy Outlook, 2015, París.

_-(2012), Oil and Gas Emergency Policy - China 2012 Update, París.

Altomonte, H. (2013), Recursos naturales: situación y tendencias para una agenda de desarrollo regional en América Latina y el Caribe. Contribución de la Comisión Económica para América Latina y el Caribe a la Comunidad de Estados Latinoamericanos y Caribeños (LC/L.3748), Santiago, Comisión Económica para América Latina y el Caribe (CEPAL).

Altomonte, H. y R. J. Sánchez (2016), Hacia una nueva gobernanza de los recursos naturales en América Latina y el Caribe, Libros de la CEPAL, № 139 (LC/G.2679-P), Santiago, Comisión Económica para América Latina y el Caribe (CEPAL).

Alves, A. C. (2013), "Chinese economic statecraft: a comparative study of China's oil backed loans in Angola and Brazil", Journal of Current Chinese Affairs, vol. 42, $\mathrm{N}^{\circ} 1$.

ANP (Agencia Nacional de Petróleo, Gas Natural y Biocombustibles) (2014), "Consórcio vence $1^{\text {a }}$ rodada de licitações do pré-sal", 4 de noviembre [en línea] http://www.bdep.gov.br/?pg=6550\&m=libra\&t1=\&t2=li bra\&t3=\&t4=\&ar=0\&ps=1\&1464889931984.

Banco Mundial (2016), Commodity Markets Outlook, Washington, D.C., enero.

- (2014), Urban China: Toward Efficient, Inclusive, and Sustainable Urbanization, Washington, D.C.

Bárcena, A. y A. Prado (2016), El imperativo de la igualdad: por un desarrollo sostenible en América Latina y el Caribe, Buenos Aires, Siglo XXI.

Berkelmans, L. y H. Wang (2012), "Chinese urban residential construction to 2040”, RBA Research Discussion Papers, № 2012-04, Sídney, Banco de la Reserva de Australia.

Bielschowsky, R. (2009), "Sesenta años de la CEPAL: estructuralismo y neoestructuralismo", Revista CEPAL, № 97 (LC/G.2400-P), Santiago, Comisión Económica para América Latina y el Caribe (CEPAL). 
(1998), "Cincuenta años del pensamiento de la CEPAL: una reseña", Cincuenta años del pensamiento en la CEPAL: textos seleccionados, Santiago, Comisión Económica para América Latina y el Caribe (CEPAL)/Fondo de Cultura Económica.

Carvalho, P. S. L. y otros (2014), "Minério de ferro", BNDES Setorial, N 39, Río de Janeiro, Banco Nacional de Desarrollo Económico y Social (BNDES).

CEPAL (Comisión Económica para América Latina y el Caribe) (2014), Pactos para la igualdad: hacia un futuro sostenible (LC/G.2586(SES.35/3)), Santiago.

(1995), América Latina y el Caribe: políticas para mejorar la inserción en la economía mundial, Libros de la CEPAL, No 40 (LC/G.1800/Rev.1-P), Santiago.

_(1985), "Crisis y desarrollo: presente y futuro de América Latina y el Caribe" (LC/L.332(Sem.22/3)), vol. 1, Santiago.

(1951), Estudio Económico de América Latina, 1949 (E/CN.12/164/Rev.1), Nueva York, Naciones Unidas.

Chen, T. y M. Pérez Ludeña (2014), "Chinese foreign direct investment in Latin America and the Caribbean", serie Desarrollo Productivo, N 195 (LC/L.3785), Santiago, Comisión Económica para América Latina y el Caribe (CEPAL).

CIARA (Cámara de la Industria Aceitera de la República Argentina) (s/f), "Estadísticas" [en línea] http://www. ciaracec.com.ar/homeCiara.php.

Clever, J. y W. Xinping (2016), "Prospects for China's oilseed market remain strong", Departamento de Agricultura de los Estados Unidos [en línea] https://gain.fas.usda.gov/Recent\%20GAIN\%20Publications/ Oilseeds\%20and\%20Products\%20Annual_Beijing_China\%20-\%20Peoples\%20Republic\%20of_3-292016.pdf.

Coates, B. y N. Luu (2012), "China's emergence in global commodity markets”, Economic Roundup, № 1.

Corrêa, A. P. (2015), "Industrialização, demanda energética e indústria de petróleo e gás na China”, China em transformação: dimensões econômicas e geopolíticas do desenvolvimento, M. A. Macedo Cintra, E. B. da Silva Filho y E. Costa Pinto (orgs.), Río de Janeiro, Instituto de Investigación Económica Aplicada (IPEA).

Di Filippo, A. (1998), "La vision centro-periferia hoy", Revista de la CEPAL, número extraordinario (LC/G.2037-P), Santiago, Comisión Económica para América Latina y el Caribe (CEPAL).

Dos Santos, T. (1970), "The structure of dependence", The American Economic Review, vol. 60, № 2, Nashville, Tennessee, American Economic Association.

Downs, E. (2011), Inside China, Inc: China Development Bank's Cross-Border Energy Deals, Washington, D.C., John L. Thornton China Center at Brookings.

Dunning, J. H. (1988), "The eclectic paradigm of international production: a restatement and possible extensions", Journal of International Business Studies, vol. 19, №1, Palgrave Macmillan.

EIA (Administración de Información Energética) (2015), "China”, 14 de mayo [en línea] https://www.eia.gov/ beta/international/analysis.php?iso=CHN. (2014), International Energy Outlook, 2014, septiembre.

Gale, F., J. Hansen y M. Jewison (2015), "China's growing demand for agricultural imports", USDA-ERS Economic Information Bulletin, No 136, Washington, D.C., Economic Research Service.

Gallagher, K. P., A. Irwin y K. Koleski (2013), “¿Un mejor trato?: análisis comparativo de los préstamos chinos en América Latina”, Cuadernos de Trabajo del CECHIMEX, №19, Ciudad de México, Universidad Nacional Autónoma de México (UNAM).

Gallagher, K. P. y M. Myers (2014), "China-Latin America Finance Database”, The Dialogue [en línea] http:// www.thedialogue.org/map_list/.

Ghose, B. (2014), "Food security and food self-sufficiency in China: from past to 2050", Food and Energy Security, vol. 3, N², Wiley.

González-Vicente, R. (2013), "Development dynamics of Chinese resource-based investment in Peru and Ecuador", Latin American Politics and Society, vol. 55, №1, Cambridge University Press.

Hofman, I. y P. Ho (2012), "China's 'developmental outsourcing': a critical examination of Chinese global 'land grabs' discourse”, The Journal of Peasant Studies, vol. 39, № 1, Routledge.

Holloway, J., I. Roberts y A. Rush (2010), "China's steel industry", RBA Bulletin, Sídney, Banco de la Reserva de Australia, diciembre.

Huo, H. y M. Wang (2012), "Modeling future vehicle sales and stock in China", Energy Policy, vol. 43, Amsterdam, Elsevier.

Jian, Z. (2011), China's Energy Security: Prospects, Challenges, and Opportunities, Washington, D.C., The Brookings Institution. 
Jiang, J. y C. Ding (2014), Update on Overseas Investments by China's National Oil Companies: Achievements and Challenges since 2011, París, Organización de Cooperación y Desarrollo Económicos (OCDE)/ Agencia Internacional de la Energía (AlE).

Jiang, J. y J. Sinton (2011), Overseas Investments by Chinese National Oil Companies: Assessing the Drivers and Impacts, París, Organización de Cooperación y Desarrollo Económicos (OCDE)/Agencia Internacional de la Energía (AlE).

Koch-Weser, I. (2015), Chinese Energy Engagement with Latin America: A Review of Recent Findings, Washington, D.C., Inter-American Dialogue.

Love, J. L. (2007), "The Latin American contribution to center-periphery perspectives: history and prospect", The Other Canon Foundation and Tallinn University of Technology Working Papers in Technology Governance and Economic Dynamics, № 10, TUT Ragnar Nurkse Department of Innovation and Governance.

Maciel, G. da C. A. (2015), "Recursos naturais e desenvolvimento econômico: bênção, maldição ou oportunidade?", tesis de doctorado, Río de Janeiro, Instituto de Economia, Universidad Federal de Río de Janeiro (UFRJ).

Medeiros, C. A. (2011), "Ascenção chinesa e as matérias-primas", Brasil e China no Reordenamento das relações Internacionais: Desafios e Oportunidades, Brasilia, Fundación Alexandre de Gusmão. (2008), "China: desenvolvimento econômico e ascensão internacional” [en línea] http://www.excedente. org/artigos/china-desenvolvimento-economico-e-ascensao-internacional/.

Myers, M., K. P. Gallager y F. Yuan (2016), Chinese Finance to LAC In 2015: Doubling Down, The Dialogue [en línea] https://www.thedialogue.org/wp-content/uploads/2016/02/Dialogue-LoansReport-v4-lowres.pdf.

Myers, M. y G. Jie (2015), China's Agricultural Investment in Latin America: A Critical Assessment, The Dialogue [en línea] http://www.thedialogue.org/wp-content/uploads/2015/06/Chinas-Agricultural-Investment-inLatin-America.pdf.

Nolte, D. (2013), "The dragon in the backyard: US visions of China's relations toward Latin America", Papel Político, vol. 18, № 2, Bogotá.

Oliveira, G. de L. T. (2015), "Chinese and other foreign investments in the Brazilian soybean complex", Documento de Trabajo, № 9 [en línea] https://www.tni.org/files/download/bicas_working_paper_9_oliveira.pdf.

Oliveira, G. de L. T. y S. Hecht (2016), "Sacred groves, sacrifice zones and soy production: globalization, intensification and neo-nature in South America", The Journal of Peasant Studies, vol. 43, № 2, Routledge.

OPEP (Organización de Países Exportadores de Petróleo) (2015), World Oil Outlook, 2015, Viena.

Ortiz Velásquez, S. (2016), "Monitor de la OFDI de China en América Latina y el Caribe: aspectos metodológicos" [en línea] http://www.redalc-china.org/monitor/images/pdfs/Publicaciones/Ortiz_2016_Monitor_OFDI_ china_metodologicos.pdf.

Paz, G. S. (2012), "China, United States and hegemonic challenge in Latin America: an overview and some lessons from previous instances of hegemonic challenge in the region", The China Quarterly, vol. 209, Cambridge University Press.

Peine, E. K. (2013), "Trading on pork and beans: agribusiness and the construction of the Brazil-Chinasoy-pork commodity complex", The Ethics and Economics of Agrifood Competition, H. S. James (ed.), Dordrecht, Springer.

PETROBRAS (Petróleo Brasileiro) (2016), "Assinatura de termo de compromisso com o CDB", 26 de febrero [en línea] http://www.investidorpetrobras.com.br/pt/comunicados-e-fatos-relevantes/fato-relevanteassinatura-de-termo-de-compromisso-com-o-cdb.

(2017) [en línea] http://www.investidorpetrobras.com.br/pt/comunicados-e-fatos-relevantes/pre-pagamentode-emprestimo-e-contratacao-de-novo-financiamento-com-o-china-development-bank.

Prebisch, R. (1949), "El desarrollo económico de América Latina y algunos de sus principales problemas" (E/CN.12/89), Santiago, Naciones Unidas.

Ray, R., K. Gallagher y R. Sarmiento (2016), "China-Latin America economic bulletin: 2016 edition”, Discussion Paper, № 2016-3, Boston, Universidad de Boston.

República Bolivariana de Venezuela (2014), "Venezuela y China producirán un millón de barriles diarios de petróleo", 14 de mayo [en línea] http://china.embajada.gob.ve/index.php?option=com_content\&view=article \&id $=1087 \% 3$ Avenezuela-y-china-produciran-un-millon-de-barriles-diarios-de-petroleo\&catid=3\%3Anoticiasde-venezuela-en-el-mundo\&ltemid=17\&lang=es.

REUTERS (2014), "Grande projeto agrícola da China na Bahia é, até agora, um campo vazio", 4 de abril [en línea] http://br.reuters.com/article/businessNews/idBRSPEA3303V20140404?sp=true.

Rocha, F. F. (2016), "Acesso chinês a recursos naturais na América Latina", Río de Janeiro, Instituto de Economia, Universidad Federal de Río de Janeiro (UFRJ). 
Rodríguez, O. (2006), El estructuralismo latinoamericano, Ciudad de México, Siglo XXI/Comisión Económica para América Latina y el Caribe (CEPAL).

(1981), La teoría del subdesarrollo de la CEPAL, Ciudad de México, Siglo XXI.

Roldán, A. y otros (2016), La presencia de China en América Latina: comercio, inversión y cooperación económica, Bogotá, Universidad EAFIT.

Rosen, D. H. y T. Houser (2007), "China Energy: A Guide for the Perplexed" [en línea] https://piie.com/ publications/papers/rosen0507.pdf.

Sachs, J. D. y A. M. Warner (1995), "Natural resource abundance and economic growth", NBER Working Paper, №5398, Cambridge, Massachusetts, Oficina Nacional de Investigaciones Económicas.

Sanderson, H. y M. Forsythe (2012), China's Superbank: Debt, Oil and Influence - How China Development Bank is Rewriting the Rules of Finance, Singapur, John Wiley \& Sons.

Sharma, S. (2014), The Need for Feed: China's Demand for Industrialized Meat and its Impacts, Instituto de Política Agrícola y Comercial [en línea] https://www.iatp.org/sites/default/files/2017-5/2017_05_03_ FeedReport_f_web_0.pdf.

Sunkel, O. (1970), "Desarrollo, subdesarrollo, dependencia, marginación y desigualdades espaciales: hacia un enfoque totalizante", EURE, vol. 1, № 1, Santiago.

Vale (2013), "Vale e China: 40 anos de parceria 1973-2013" [en línea] http://www.vale.com/PT/aboutvale/ news/Documents/china-quiz-8/pdf/40anosValeChina.pdf.

Westcott, P. y J. Hansen (2016), "USDA agricultural projections to 2025", Departamento de Agricultura de los Estados Unidos [en línea] https://www.ers.usda.gov/publications/pub-details/?pubid=37818.

Wesz Junior, V. J. (2014), "O mercado da soja no Brasil e na Argentina: semelhanças, diferenças e interconexões", Revista de Ciencias Sociales, vol. 4, № 1.

— (2011), Dinâmicas e estratégias das agroindústrias de soja no Brasil, Río de Janeiro, E-papers.

Wilkinson, J., V. J. Wesz Junior y A. R. M. Lopane (2015), "Brazil, the Southern Cone, and China: the agribusiness connection", BRICS Initiative for Critical Agrarian Studies (BICAS) Working Paper, № 16.

Winter, J. y otros (2013), "Pacific Basin heavy oil refining capacity", SPP Research Paper, vol. 6, № 8, Calgary, The School of Public Policy.

Wong, J. e Y. Huang (2012), "China's food security and its global implications", China: An International Journal, vol. 10, № 1.

Xing. L. y P. Goldsmith (2013), "Improving Chinese soybean meal demand estimation by addressing the noncommercial: commercial feed gap", China Agricultural Economic Review, vol. 5, № 4, Emerald Publishing.

Yu, Y. (2011), "Identifying the linkages between major mining commodity prices and China's economic growth - Implications for Latin America", IMF Working Papers, No WP/11/86, Washington, D.C., Fondo Monetario Internacional (FMI).

Zhang, L. y otros (2015), "The future of copper in China: a perspective based on analysis of copper flows and stocks", Science of the Total Environment, vol. 536, Amsterdam, Elsevier. 